\title{
Metodologia para gerenciar projetos de pesquisa e desenvolvimento com foco em produtos: uma proposta*
}

\author{
Andréia Azevedo Pinheiro** \\ Antônio Carlos Siani*** \\ Jislaine de Fátima Guilhermino**** \\ Maria das Graças Muller de Oliveira Hen- \\ riques $* * * * *$ \\ Cristiane Machado Quental****** \\ Ana Paula Brum Pizarro*******
}

\begin{abstract}
S UMÁRIO: 1. Introdução; 2. Contextualização/base conceitual da metodologia desenvolvida; 3. O Instituto de Tecnologia em Fármacos (Far-Manguinhos); 4. A necessidade de uma metodologia de gestão; 5. O modelo de gestão adotado; 6 . Outras aplicações da metodologia desenvolvida; 7. Considerações finais.
\end{abstract}

* Artigo recebido em nov. 2005 e aceito em mar. 2006.

** Assessora em planejamento do Instituto Oswaldo Cruz/Fiocruz. Mestre em saúde pública. Endereço: Av. Brasil, 4.365 - Manguinhos - CEP 21045-900 — Rio de Janeiro, RJ, Brasil. E-mail: andreia@ioc.fiocruz.br.

*** Tecnologista sênior do Far-Manguinhos/Fiocruz. Doutor em química. Endereço: Rua Sizenando Nabuco, 100 - Manguinhos - CEP 21041-250, Rio de Janeiro, RJ, Brasil. E-mail: siani@far.fiocruz.br.

**** Tecnologista pleno do Far-Manguinhos/Fiocruz. Doutoranda em tecnologia de processos químicos e bioquímicos. Endereço: Rua Sizenando Nabuco, 100 - Manguinhos - CEP 21041-250, Rio de Janeiro, RJ, Brasil. E-mail: jislaine@far.fiocruz.br.

***** Pesquisadora titular do Far-Manguinhos/Fiocruz. Doutora em biologia celular e molecular. Endereço: Rua Sizenando Nabuco, 100 - Manguinhos - CEP 21041-250, Rio de Janeiro, RJ, Brasil. E-mail: gracahen@far.fiocruz.br.

****** Coordenadora adjunta do Mestrado Profissional em Gestão de C\&T em Saúde, Escola Nacional em Saúde Pública Sérgio Arouca/Fiocruz. Doutora em administração de empresas. Endereço: Av. Leopoldo Bulhões, 1.480 — Manguinhos — CEP 21041-210, Rio de Janeiro, RJ, Brasil. E-mail: cquental@fiocruz.br.

******* Assessora em gerência de projetos do Centro de Desenvolvimento Tecnológico em Saúde/ Fiocruz. Doutora em engenharia de produção. Endereço: Av. Brasil, 4.365 — Manguinhos — CEP 21045900, Rio de Janeiro, RJ, Brasil. E-mail: apbrum@fiocruz.br. 
Summary : 1. Introduction; 2. Context/conceptual framework of the methodology developed; 3. The Pharmaceutical Technology Institute (Far-Manguinhos); 4. The need for a management methodology; 5 . The management model adopted; 6 . Other applications of the methodology; 7. Final remarks.

P ALA VRA S-CHA VE : gestão em P\&D; metodologia de gestão; gerenciamento de projetos; estrutura organizacional para $\mathrm{P} \& \mathrm{D}$.

KEY WORDS: R\&D management; management methodology; project management; organizational structure for R\&D.

As atividades de pesquisa e desenvolvimento (P\&D) realizadas nos institutos públicos de pesquisa (IPPs) têm como característica uma gestão arraigada nas premissas acadêmicas, que priorizam a geração e difusão do conhecimento. Em contrapartida, a necessidade de competitividade tecnológica no mercado e a pressão pela participação, como instrumentos da política pública do esforço nacional rumo à inovação, têm pressionado os IPPs para a busca por resultados mais concretos. Esse fato acarreta a geração de grandes lacunas nos processos relacionados à gestão, induzindo a uma constante necessidade de aperfeiçoamento gerencial, no sentido de criar e melhorar ferramentas que contribuam para adequá-la à nova realidade. Este artigo propõe uma metodologia de gestão de projetos de $\mathrm{P} \& \mathrm{D}$, que se baseia no direcionamento dos projetos de pesquisa para a obtenção de produtos, e considera suas características multidisciplinares e interdisciplinares e a incerteza inerentes a esse processo. Essa metodologia foi desenvolvida no Instituto de Tecnologia de Fármacos da Fiocruz e é proposta como um modelo original para instituições semelhantes.

Management methodology for product-oriented $R \& D$ projects:

a proposal

The Research and Development (R\&D) activities carried out at public research institutes have a strongly rooted academic-like management which focuses on knowledge improvement. On the other hand, the need for technological competitiveness and contribution in the national effort towards innovation has lead Brazilian organizations to search for more concrete results: products. This fact accounts for huge gaps in management-related processes and a constant need for managerial improvements in order to generate and perfect tools suitable to a new reality. This article proposes a $R \& D$ project management methodology focused on research projects that aim at new technological products taking into consideration the multidisciplinary and interdisciplinary aspects and the uncertainty inherent to this process. It presents the case of the Pharmaceutical Technology Institute, a unit of the Oswaldo Cruz Foundation, and proposes an original model for similar institutes.

\section{Introdução}


A demanda crescente pela transformação do conhecimento científico em resultados práticos para a sociedade e pela geração de inovações que possam contribuir para o fortalecimento da competitividade do setor produtivo nacional constitui um grande e complexo desafio a ser enfrentado pelos institutos públicos de pesquisa (IPPs).

Grande parte desses institutos opera obedecendo a uma lógica de cunho fortemente acadêmico e, por isso, o atendimento a essa demanda requer, entre outras ações, ênfase no desenvolvimento tecnológico e uma maior aproximação com os setores produtivos, público e privado. As dificuldades e entraves existentes no decurso desse trajeto são de diversas naturezas, resultado da complexidade desses processos, em função da multidisciplinaridade que pauta toda a cadeia de atividades envolvida na geração de produtos e do elevado grau de incerteza em relação aos resultados esperados - fato que dificulta a previsão dos riscos relacionados a esses investimentos (Maximiano, 2002).

Esse gerenciamento é complexo, mas fundamental para as perspectivas de sucesso na obtenção de produtos. Entretanto, os IPPs defrontam-se com dificuldades para implementá-lo, principalmente pela tensão antagônica entre a cultura e a forma de operação, necessárias ao desenvolvimento tecnológico e aquelas em vigor na academia, dificultando o processo de gestão.

Este artigo reporta a experiência do Instituto de Tecnologia em Fármacos (FarManguinhos), a unidade da Fundação Oswaldo Cruz (Fiocruz) voltada para a pesquisa, o desenvolvimento e a produção de medicamentos, dentro da área específica de P\&D de medicamentos fitoterápicos. O foco do artigo é o processo de gestão implantado entre 1996 e 2002, que considera a organização desse processo, dentro de uma metodologia desenvolvida para aquela área específica, assim como uma extrapolação desse contexto para adaptação a outros IPPs que tenham como meta a geração de produtos. De fato, a metodologia desenvolvida já vem sendo adaptada para outras unidades da Fiocruz.

\section{Contextualização/base conceitual da metodologia desenvolvida}

Segundo Caldas (2001), a capacidade de formular, identificar, priorizar e avaliar criticamente as demandas é condição estratégica para o direcionamento dos esforços institucionais no país, pois seria impossível imaginar que se opte por investir em todas as áreas de conhecimento e em todas as oportunidades de desenvolvimento tecnológico e inovação ao mesmo tempo. Daí a necessidade de se estabelecer uma cultura institucional de priorizações e com focos bem definidos.

Uma vez as prioridades institucionais identificadas, desenham-se mais nítidas as configurações para as áreas de política, planejamento e gestão dos IPPs quanto à formulação e utilização de mecanismos, instrumentos e metodologias gerenciais capazes de induzir, integrar e reorientar suas atividades científicas e tecnológicas na direção do 
atendimento dessas prioridades. É nesse contexto que se insere a proposta para o estabelecimento de uma metodologia de gestão de projetos de pesquisa e desenvolvimento tecnológico com vistas à obtenção de novos produtos e processos.

Para Valeriano (1998), projeto é entendido como um conjunto de ações, realizadas de forma coordenada por uma organização temporária, onde são alocados os insumos necessários para alcançar um objetivo em um determinado prazo. Técnicas de administração voltadas para o planejamento, organização, execução e controle, utilizadas no curso do ciclo de vida de um projeto, são largamente estudadas e disseminadas, e facilitam o controle das atividades inseridas dentro do conceito de um projeto.

A administração de projetos sistematizou suas práticas, convertendo-se em uma disciplina nos anos 1980, consolidando-se num movimento para identificar as áreas do conhecimento que concentram as técnicas e os conceitos mais importantes para o gerenciamento de projetos (Maximiano, 2002). Esse movimento foi liderado pelo Project Management Institute (PMI), que produziu o Guide to the project management body of knowledge - PMBOK® (1996). É um documento que sistematiza o campo da administração de projetos, contribuindo para a criação de uma linguagem comum e fornecendo as bases para programas de treinamento e educação em administração de projetos.

Com base nos conceitos do PMBOK, foi criada a metodologia de gestão apresentada neste artigo, respeitando as características específicas da área em foco: P\&D de medicamentos de origem vegetal.

Para começar, todos os projetos de P\&D convivem com um componente de incerteza com relação aos seus resultados. Quanto maior o desconhecimento com relação aos resultados esperados, maior o risco relacionado ao projeto. Para fazer frente a isso a metodologia proposta é dividida em etapas, isto é, ao final de cada etapa, o projeto é reavaliado para decidir-se por sua continuidade ou não.

Os projetos de P\&D se deparam com duas abordagens que são claramente distinguíveis quando se analisa esse processo. A pesquisa, na maioria das organizações, está baseada em uma estrutura acadêmica, disciplinar, com alto grau de especificidade, enquanto o desenvolvimento tecnológico é multidisciplinar e deve focar o mercado. Da tensão entre os "falsos dilemas" dessas duas abordagens decorrem os impactos, que se refletem negativamente no processo de gestão.

A produção científica é medida pelo número e qualidade de artigos gerados pelo pesquisador: quanto maior o número de publicações, mais oportunidades de aprovação de recursos junto aos órgãos de fomento. Esse fato açoda a publicação prematura de resultados que poderiam ser protegidos, patenteados e posteriormente negociados.

As parcerias informais entre pesquisadores e grupos de pesquisa, que alimentam a troca de conhecimento científico na academia, tornam-se um grande problema, na perspectiva de um produto ser desenvolvido, se as regras sobre os direitos 
advindos da tecnologia, eventualmente gerada, não forem previamente anuídas e formalizadas.

A ausência de registros de atividades que está relacionada também à cultura acadêmica onde o projeto é “do pesquisador” e não da instituição em que ele está inserido, não raro provoca a perda de informações essenciais, e obriga que muitos trabalhos tenham que ser reiniciados, gerando uma série de percalços e, mormente, os prejuízos com o retrabalho e o refinanciamento de uma mesma atividade.

Ainda, a multidisciplinaridade (ou diversidade de especialidades profissionais necessárias para a realização dos projetos), o número de pessoas envolvidas, as instalações físicas necessárias, a diversidade e o volume de informações a serem processadas e rastreadas; a real duração do projeto e o número de parceiros envolvidos para o desenvolvimento e a conclusão do projeto são fatores que denotam a complexidade desses projetos e apontam para a necessidade de um assíduo acompanhamento e controle das atividades.

Essas são algumas das questões que sobressaem quando se discutem modelos de gestão de P\&D. Esses aspectos conformam a especificidade da metodologia desenvolvida. Não são, entretanto, suficientes se não vêm articulados com contexto, estrutura e processos adequados para sua implementação (Debackere, 2000).

Debackere (2000) sustenta ainda que, para uma maior chance de sucesso na implementação de novos modelos de gestão, no desenvolvimento de contexto, estrutura e processos adequados, os valores fundamentais da pesquisa e do ensino devem ser complementados, em vez de se tornarem empecilhos, no engajamento e envolvimento das universidades e institutos de pesquisa no emergente processo de inovação industrial e empresarial.

O autor explicita que o “contexto” está relacionado à cultura e à história da organização, que moldam e configuram as normas, valores e as atitudes dos pesquisadores diante da combinação dos esforços da pesquisa e da inovação, da pesquisa dirigida pela curiosidade com a busca ativa pelas oportunidades relevantes de mercado fora da mesma pesquisa.

O processo de incorporação da cultura do desenvolvimento tecnológico no escopo dos projetos de pesquisa tradicionais passa, segundo pesquisadores da Fiocruz entrevistados por Pinheiro (2004), por ações em duas frentes: na sensibilização dos pesquisadores e no investimento para criação de infra-estrutura adequada. Ressaltase a necessidade de se construir primeiramente o suporte adequado para um modelo de gestão que valorize as perspectivas de sucesso na obtenção de produtos.

A “estrutura” proporciona mecanismos organizacionais e de incentivo adequados, enquanto “processos” referem-se às operações do dia-a-dia de criação do conhecimento e gerenciamento das inovações no ambiente do desenvolvimento acadêmico. $\mathrm{O}$ autor aponta ainda para a propriedade intelectual e para o gerencia- 
mento dos novos riscos da criação como processos centrais no gerenciamento da P\&D acadêmica como negócio.

\section{O Instituto de Tecnologia em Fármacos (Far-Manguinhos)}

Criado em 1956 e integrado como uma das unidades da Fiocruz na década de 1970, o Instituto de Tecnologia em Fármacos (Far-Manguinhos) desenvolve tecnologia e produz medicamentos de interesse da saúde pública, priorizando os programas estratégicos do Ministério da Saúde e atendendo de forma complementar as secretarias estaduais e municipais de Saúde (Brasil, 2002). A unidade produziu em 2002 cerca de 1,4 milhão de comprimidos, cápsulas e outras unidades farmacêuticas relacionadas aos medicamentos considerados essenciais, dentro do critério do SUS para o atendimento à população, apresentando um faturamento em torno de R\$ 211 milhões. Far-Manguinhos também se dedica à pesquisa e à produção de medicamentos que atendam as necessidades da população, em consonância com os desígnios do Sistema Único de Saúde (SUS).

\section{A necessidade de uma metodologia de gestão}

A implantação de uma nova metodologia gerencial em Far-Manguinhos emanou basicamente da necessidade de se criarem critérios de decisão com vistas ao alinhamento estratégico dos projetos de pesquisa em curso, num ambiente onde ainda eram fortes os ideais de liberdade de pesquisa e as reações a qualquer tipo de ingerência por parte da gestão institucional no trabalho do pesquisador.

Tal tensão foi enfim sobrepujada pela introdução de um desafio, um fato disparador: uma ação orçamentária do Ministério da Ciência e Tecnologia (MCT), incluída no Plano Plurianual do governo federal, no Programa de Biotecnologia e Recursos Genéticos, que previa o desenvolvimento de 16 produtos fitoderivados, a partir da diversidade vegetal brasileira, teve seu gerenciamento e sua execução alocados ao Far-Manguinhos.

Para cumprir esse objetivo, era insuficiente uma gestão tradicional, emanando de uma estrutura institucional departamental; esta voltada para atender basicamente aos projetos de pesquisa, já que no campo do desenvolvimento tecnológico são exigidas especiais atenções às normas, padrões, regulamentos e legislações específicas na grande maioria das vezes, desconsideradas nas atividades de pesquisa básica.

Assim iniciou-se o processo de diagnóstico ante a situação desejada, o que exigiu: levantar as lacunas existentes no processo para o alcance das metas traçadas (produtos tecnológicos); reorganizar as áreas físicas e adequar seu gerenciamento, 
de modo a facilitar o acompanhamento físico-financeiro; integrar as atividades multidisciplinares tornando-as interdisciplinares; identificar as parcerias necessárias.

Todas essas questões foram amadurecidas e discutidas internamente, numa empreitada que envolveu atores de duas áreas técnicas de fundamental importância dentro do necessário encadeamento de fases para o desenvolvimento tecnológico de produtos naturais: fitoquímica e farmacologia, ou seja, estudos de constituição molecular e estudos de eficácia - tendo como foco principal o desenvolvimento de produtos.

\section{O modelo de gestão adotado}

\section{Estruturação funcional da área}

Uma característica marcante e interessante na inovação médica é sua crescente dependência de pesquisas interdisciplinares (Albuquerque e Cassiolato, 2000). Em medicamentos, por exemplo, uma nova droga envolve o trabalho de químicos, biólogos moleculares, imunologistas, engenheiros químicos e outros especialistas. Ou seja, a produção de inovações no setor da saúde tem por pré-requisito uma estrutura de formação universitária e de pós-graduação abrangente e sofisticada, devido ao tipo de interação e interdisciplinaridade que ela apresenta.

Com a participação de técnicos e pesquisadores nas áreas de gestão de projetos, processos e produção, química e farmacologia e com base na legislação e na regulamentação específicas de cada área disciplinar envolvida, preconizada pelo principal órgão fiscalizador, a Agência Nacional de Vigilância Sanitária (Anvisa), o primeiro passo foi identificar as abordagens multidisciplinares envolvidas no processo. A seguinte seqüência de áreas envolvidas do início ao fim do ciclo de desenvolvimento, denominadas então de áreas mestras, foi estabelecida: botânica > agronômica > química > farmacêutica > biomédica e médica.

Em seguida, a partir da necessidade de sistematização e direcionamento das ações, foi identificada dentro das áreas mestras a seqüência das principais atividades disciplinares envolvidas no processo de desenvolvimento, conforme ilustrado na figura. 


\section{Seqüência das atividades envolvidas no desenvolvimento de fitoterápicos}

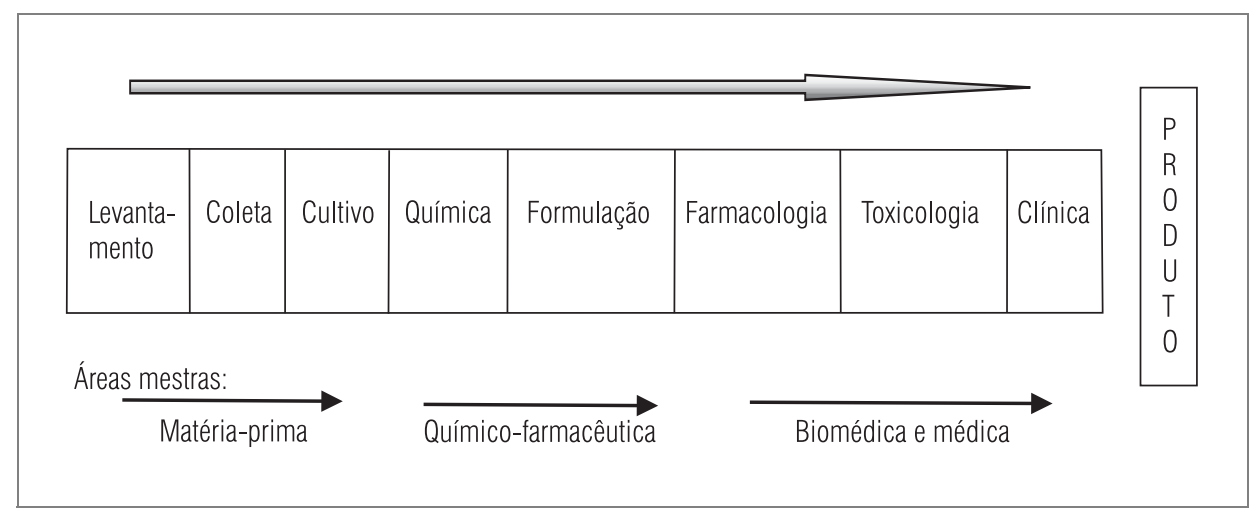

Fonte: Adaptado de Pizarro (2003).

A identificação das áreas mestras, das atividades e das fases envolvidas no processo de desenvolvimento ratificou a necessidade de criação de uma estrutura técnicogerencial multidisciplinar, composta por especialistas que pudessem acompanhar a execução do projeto e atuar técnica e gerencialmente em fases específicas, sempre com o objetivo precípuo de direcionar os projetos de pesquisa para a obtenção de produtos, com o cuidado de não interferir — ou interferindo o mínimo possível — na pesquisa corrente na instituição, recorrente no trabalho científico do pesquisador ou de seu grupo. A primeira configuração da equipe gerencial consistiu em uma coordenação geral, duas gerências e três consultorias, cujas principais atividades resumiam-se em:

t direcionar os projetos de pesquisa para a obtenção de produtos;

t realizar estudos de viabilidade técnico-econômica periodicamente, em conjunto com a equipe multidisciplinar, dentro de um processo formalmente gerenciado;

t estabelecer critérios para: definições de prioridades, negociações prévias das parcerias, absorções de novos projetos, continuidade dos projetos em andamento e construção de interface com as demais fases da cadeia do processo de desenvolvimento.

\section{A gestão dos projetos}

Calcados nos conceitos do PMI, após a criação da equipe e da definição dos objetivos, iniciou-se a elaboração do escopo de trabalho, uma das tarefas preconizadas pelo PMBOK, que consistiu na definição detalhada de todos os passos técnicos e científicos com uma 
abordagem gerencial, o que é particularmente importante no caso de projetos em P\&D. Nesse escopo são traçados os passos necessários desde a fase inicial da pesquisa até o desenvolvimento do produto, de forma a otimizar tempo e recursos, respaldada pela regulamentação específica da área. Esse escopo, elaborado a partir da colaboração de pesquisadores/consultores nas áreas de química e farmacologia, foi dividido em três níveis (I, II, III) que representavam as fases do avanço técnico dos projetos (pesquisa, pesquisa em estágio avançado e desenvolvimento tecnológico), conforme apresentado no quadro 1.

A pesquisa em estado avançado caracterizava-se pelos primeiros resultados multidisciplinares obtidos a partir principalmente da investigação química e farmacológica. O documento geral, sistematizado no quadro 1 , aplica-se ao desenvolvimento de qualquer fitoterápico. A partir desse documento, cada pesquisador identificava e relacionava aos seus itens as atividades de seus projetos, construindo assim a estrutura analítica de cada projeto.

O diferencial estava em não só listar as atividades que estavam sendo desenvolvidas com um cronograma básico de execução, mas também em conhecer o ciclo de vida dos projetos com uma visão abrangente que englobasse todas as áreas envolvidas até a finalização do "produto" e não dos resultados para a publicação de um "artigo". Com esse "caminho conhecido", denominado escopo, foi possível trabalhar fatores de risco, custo, realizar o planejamento econômico, identificar em que momentos seria necessário trabalhar com parcerias e mapeá-las com antecedência, levantar a patenteabilidade ou solicitar o pedido de patente no momento oportuno. Com base nesses dados foi traçado o acompanhamento dos projetos.

\section{Quadro 1}

Escopo de trabalho do desenvolvimento de produtos fitoterápicos

Nível I

1. Levantamento bibliográfico

2. Coleta

3. Identificação botânica

4. Prospecção química

s obtenção de extratos

s fracionamento

5. Ensaio farmacológico primário (in vitro)

6. Toxicologia: citotoxicidade

7. Levantamento da patenteabilidade

8. Avaliação da viabilidade técnico-econômica
Nível II

1. Avaliação farmacológica in vivo

2. Toxicidade aguda (dose única)

3. Padronização (definição dos marcadores químicos por atividade farmacológica)

4. Padronização morfológica

5. Levantamento da disponibilidade da matériaprima vegetal

6. Toxicologia do extrato padronizado: toxicidade aguda (doses repetidas)

7. Reavaliação da viabilidade técnicoeconômica 
1. Produção da planta:

1.1. Estabilização e melhoramento

1.2. Desenvolvimento de mudas padronizadas

1.3. Horticultura/cultivo/adubação

1.4. Coleta e identificação botânica

1.5. Compra da matéria-prima

2. Processamento primário

2.1. Lavagem/seleção/esterilização

s drenagem/secagem

s armazenamento

3. Processamento secundário

3.1. Moagem

s extração/destilação

s concentração

s outros

4. Controle da qualidade da matéria-prima

4.1. Confirmação farmacognóstica

4.2. Análise quantitativa e qualitativa dos princípios ativos e/ou marcadores químicos

5. Desenvolvimento de formulação

5.1. Formulação em sólidos, semi-sólidos e líquidos

$s$ ensaios dos excipientes

$\mathrm{s}$ produto final

5.2. Teste de estabilidade
6. Controle da qualidade do produto acabado

6.1. Controle químico (dosagem)

6.2. Controle microbiológico

7. Complementação farmacológica

7.1. Extrato padronizado/produto (in vitro)

7.2. Extrato padronizado/produto (in vivo)

8. Complementação toxicológica extrato padronizado/substância isolada/produto

8.1. Toxicidade aguda

8.2. Toxicidade crônica

8.3. Toxicidade local

8.4. Toxicidade específica

8.5. Carcinogenicidade

8.6. Teratogenicidade

9. Ensaios clínicos

9.1. Preparação do dossiê para o Comitê de Ética em Pesquisas em Seres Humanos

9.2. Ensaios clínicos fases I, II, III, IV

10. Transferência de tecnologia

11. Registro na Anvisa

Desenvolvimento tecnológico

Fonte: Adaptado de Pizarro (2003).

Do ponto de vista gerencial, o escopo de trabalho elaborado permitia uma classificação dos projetos de acordo com seu avanço técnico, sendo possível identificar quais e quantos projetos estavam nos níveis I, II ou III. Dessa forma, a equipe pôde enquadrar os 80 projetos na área de produtos naturais em andamento no instituto.

Esse panorama permitiu a construção de uma metodologia que indicava as prioridades e direcionava a atuação da equipe gerencial, visando atender as especificidades técnicas e gerenciais dos projetos em cada nível do escopo de trabalho. A última fase do processo (nível III), por exemplo, requeria a intensa participação da equipe multidisciplinar, pois gerenciava a pesquisa já fora da bancada, e o papel do pesquisador resumia-se a acompanhar e supervisionar o seu desenvolvimento.

Para cada projeto foi construído um portfólio contendo todas as informações dos projetos, onde se incluía: o responsável, a equipe, a literatura de apoio, a metodologia e os protocolos utilizados, os resultados obtidos, as parcerias potenciais, o custo estimado do projeto, o cronograma de execução, entre outras informações. 
Com base nesse dossiê, a equipe passava a realizar os estudos de viabilidade técnica, econômica, e patentária de cada projeto, além da análise sobre o seu enquadramento às normas, regulamentos e legislações específicos das áreas envolvidas.

A realização de estudos de viabilidade técnico-econômica para os 80 projetos existentes foi determinante para a identificação de projetos com maiores chances de sucesso, sob a ótica do desenvolvimento para futuras transferências tecnológicas e comercialização. Dos 80 projetos em andamento, apenas 33 foram inicialmente considerados viáveis técnica e economicamente, sendo 15 classificados como pesquisa (nível I), 15 enquadrados como pesquisa em estágio avançado (nível II), e três foram alocados na fase de desenvolvimento tecnológico (nível III). A redução do número de projetos ocorreu gradativamente durante o período de 1999 a 2001. Nesse sentido, incentivava-se positivamente a divulgação do conhecimento produzido, associado aos projetos tecnologicamente inviáveis.

Para ilustrar uma tomada de decisão a partir do enquadramento dos projetos no escopo de trabalho e da realização dos estudos de viabilidade, apresenta-se aqui o seguinte caso hipotético: um projeto identifica um princípio ativo com atividade farmacológica em um determinado vegetal. No entanto, verifica-se que além da matéria-prima ser de difícil acesso, são necessárias grandes quantidades da planta para obtenção de reduzidas quantidades de extrato. A amostra era suficiente para fins de pesquisa básica, mas inviável para a produção em escala, indicando a necessidade de se buscar alternativas.

O fluxo de informações dos projetos era sempre acompanhado por intermédio de relatórios periódicos, sob a responsabilidade do coordenador da equipe. Os portfólios e relatórios eram encaminhados aos especialistas da equipe que, com base no escopo de trabalho, realizavam a avaliação e orientavam os próximos passos do trabalho.

Em uma mesma mesa, a equipe e o pesquisador responsável pelo projeto discutiam e negociavam o resultado das avaliações realizadas sistemática e periodicamente. Durante essas reuniões, o pesquisador tinha a oportunidade de relatar as dificuldades encontradas e de buscar as possíveis soluções conjuntas com outros especialistas da equipe. Em alguns casos, dependendo da especificidade dos problemas ou dificuldades levantadas, a equipe identificava consultores ou grupos de pesquisa atuantes na mesma área ou com competências complementares, dentro ou fora da instituição, para colaborar na solução do problema ou para futuras parcerias. Não havia interferência direta por parte da equipe no trabalho científico do pesquisador, mas a indicação de adequações necessárias em fases pontuais do projeto.

O processo de desenvolvimento de produtos é altamente complexo e em cada etapa apresentam-se inúmeros entraves, alguns deles impeditivos à conclusão do projeto. $\mathrm{O}$ trabalho da equipe multidisciplinar em cada um dos projetos permitia a antecipação desses óbices, tanto para a busca da solução visando a não-interrupção do projeto, quanto para o abandono estimulado da proposta, antes que maiores investimentos fossem realizados. “(...) A resposta não pode ser simplesmente gastar mais 
em P\&D, porque mais poderá nunca ser o suficiente. A solução, ao contrário, é dispor os investimentos em P\&D mais efetivamente — ou seja, mais estratégica e eficientemente” (Roussel, Saad e Bohlin, 1992:1).

\section{A mudança de cultura}

Em Far-Manguinhos, a equipe gerencial enfrentou inicialmente sérias resistências por parte dos pesquisadores, especialmente pelo receio de ingerências despropositadas no trabalho científico. No entanto, no decurso da sua atuação junto aos grupos de pesquisa, e em virtude do entendimento sobre seus objetivos, propostas e do efetivo apoio, as resistências reduziram-se, à medida que crescia a confiança.

\section{Interfaces da gestão de processos multidisciplinares}

\section{Interfaces internas}

A gerência de projetos de P\&D dentro de uma estrutura funcional demanda a tarefa de normatização dos procedimentos das áreas técnicas e a interação com os outros departamentos da unidade, com o objetivo de garantir a otimização e racionalização na execução dos projetos. Cabe ressaltar algumas das atividades necessárias para o aprimoramento das relações internas:

t promoção de ações de integração técnica e administrativa entre as áreas funcionais;

t garantia, em conjunto com os gerentes de projetos e funcionais, da aplicação das ferramentas de acompanhamento e avaliação dos projetos da área;

t realização do diagnóstico dos entraves e dificuldades operacionais nos fluxos das atividades pertinentes a cada área funcional;

t cumprimento das ações destinadas à manutenção dos critérios de qualidade e de procedimentos operacionais envolvidos na execução dos projetos na área;

t aperfeiçoamento dos mecanismos de controle das atividades administrativas das gerências funcionais, no tocante às atividades de acompanhamento de custos e despesas em geral incluindo-se as aquisições necessárias para as áreas;

t implementação de indicadores de desempenho distintos, para avaliação dos projetos de pesquisa e desenvolvimento tecnológico. 
Interfaces externas e as parcerias para o desenvolvimento tecnológico

A partir da atribuição de custos estimados a cada uma das atividades/etapas descritas em cada um dos níveis (I, II, III) do escopo de trabalho, foi possível desenvolver um planejamento econômico para os projetos. Essa estimativa permitiu à unidade conhecer os investimentos necessários em cada projeto e no conjunto de projetos da área. Além da projeção de investimentos, foi possível, com o controle orçamentário, inferir o custo total de desenvolvimento de uma tecnologia - uma informação fundamental nos momentos de negociação, comercialização e transferência de tecnologias, ou ainda no estabelecimento de parcerias para o desenvolvimento.

O escopo de trabalho, considerado como a peça-chave do processo de construção da metodologia de gerenciamento específico da área de produtos naturais, permitiu ainda a definição de critérios para a distribuição de dividendos da comercialização de produtos desenvolvidos por meio de parcerias.

Durante o exercício de estabelecimento de parcerias envolvendo as pesquisas e o desenvolvimento de produtos, a equipe identificou a existência de inúmeros entraves burocráticos relacionados ao compartilhamento pelos parceiros dos possíveis dividendos gerados pelos produtos em questão, em especial no caso do desenvolvimento de fitoterápicos inseridos em um campo jurídico cuja legislação encontravase ainda em processo de consolidação.

Essa situação evidenciava-se nas parcerias já em curso antes da constituição da equipe, e vinha se propagando também para aquelas ainda em fase de elaboração, seja nos convênios, nos contratos de prestação de serviços, ou mesmo nas eventuais colaborações informais, levando à paralisação ou prejudicando o andamento dos projetos.

Fazia-se necessário, assim, o estabelecimento de um acordo formal, pautado pelos critérios técnicos, que fornecesse uma base clara para negociação prévia, antes do estabelecimento do compromisso da parceria entre as partes. Com esse objetivo, a equipe, com base no escopo de trabalho, ponderou e atribuiu uma pontuação a cada uma das etapas que compunham as tarefas da pesquisa e do desenvolvimento do produto. Essa pontuação vinculava-se diretamente aos ganhos advindos de uma futura comercialização de produtos. O somatório dos percentuais resultava em 100\%, consignando a integração e a conclusão do trabalho. Os ganhos eram, então, proporcionais ao trabalho executado e os acordos firmados entre as partes passaram a remeter às questões de divisão de direitos e ganhos às planilhas elaboradas, que continham as etapas e os respectivos pesos e percentuais que podiam sofrer ligeiras variações de acordo com as negociações.

O documento elaborado, que então passou a ser anexado aos contratos de parceria, apresentava ainda: os tipos de parcerias, a natureza da colaboração, e os respectivos desdobramentos que norteariam as negociações para a divisão dos ganhos. 
Por exemplo, no caso em que uma das partes arcasse com os custos de material de consumo e/ou equipamentos (parceiro 1) e a outra com o custo de mão-de-obra e com o conhecimento intelectual (parceiro 2), a distribuição seria a seguinte: $80 \%$ sobre o percentual atribuído àquela etapa específica da planilha para o parceiro 1 e $20 \%$ sobre o percentual atribuído àquela etapa específica da planilha para o parceiro 2 . Com o intuito de exemplificar a metodologia desenvolvida e promover seu melhor entendimento, apresenta-se a seguir a planilha de desenvolvimento de fitoterápicos extraída do referido documento (quadro 2).

\section{Quadro 2}

Pesos e percentuais das etapas da pesquisa e do desenvolvimento de fitoterápicos

Nível I

Peso 5

1. Levantamento bibliográfico

2. Coleta

3. Identificação botânica

4. Prospecção química

s obtenção de extratos

$s$ fracionamento

5. Ensaio farmacológico primário (in vitro)

6. Toxicologia: citotocixidade

7. Levantamento da patenteabilidade

8. Avaliação da viabilidade técnico-econômica

Nível II

1. Avaliação farmacológica in vivo

2. Toxicidade aguda (dose única) 
3. Padronização (definição dos marcadores químicos por atividade farmacológica)

1.1. Estabilização e melhoramento

1.2. Desenvolvimento de mudas padronizadas

1.3. Horticultura/cultivo/adubação

1.4. Coleta e identificação botânica

1.5. Compra da matéria-prima

2. Processamento primário

2.1. Lavagem/seleção/esterilização

2.2. Drenagem/secagem

2.3. Armazenamento

3. Processamento secundário

3.1. Moagem

3.2. Extração/destilação

3.3. Concentração

3.4. Outros

4. Controle da qualidade da matéria-prima

4.1. Confirmação farmacognóstica

4.2. Testes de pureza e integridade

4.3. Análise quantitativa e qualitativa dos princípios ativos e/ou marcadores químicos

5. Desenvolvimento de formulação

5.1. Formulação em sólidos, semi-sólidos e líquidos

$s$ ensaios dos excipientes

$s$ produto final

5.2. Teste de estabilidade

6. Controle da qualidade do produto acabado

6.1. Controle químico (dosagem)

6.2. Controle microbiológico 
7. Complementação farmacológica

7.1. Extrato padronizado/produto (in vitro)

7.2. Extrato padronizado/produto (in vivo)

8. Complementação toxicológica extrato padronizado/substância isolada/ produto

8.1. Toxicidade aguda

8.2. Toxicidade crônica

8.3. Toxicidade local

8.4. Toxicidade específica

8.5. Carcinogenicidade

8.6. Teratogenicidade

9. Ensaios clínicos

9.1. Preparação do dossiê para o Comitê de Ética em Pesquisas em Seres Humanos

9.2. Ensaios clínicos fases I, II, III, IV

10. Transferência de tecnologia

0,6

11. Registro na Anvisa

0,4

Fonte: Brasil, s.d.

É importante registrar que foram necessários quase quatro anos para a consolidação de todo esse processo e que, ao longo do trabalho, verificou-se que a meta de desenvolver quatro produtos em um ano era completamente inexeqüível, dada a complexidade e o tempo de maturação de projetos na área de produtos naturais. No entanto, os atores envolvidos, quando entrevistados por Pinheiro (2004) enfatizaram que o desafio proposto alavancou um processo de aprendizagem e treinamento que resultou na criação de uma metodologia gerencial no campo da gestão de projetos de pesquisa e desenvolvimento, considerada inovadora. No final do ano de 2002, dois produtos já se encontravam aptos a iniciarem os estudos clínicos, ou seja, em fase final do processo.

\section{Síntese da metodologia proposta}

A metodologia proposta tem como objetivo prover uma orientação aos IPPs, sendo, portanto, um conjunto de etapas que devem ser adaptadas à realidade da organização.

\begin{tabular}{|l|}
\hline \multicolumn{1}{|c|}{ Quadro 3} \\
\hline Síntese da metodologia proposta \\
\hline Macroetapas \\
\hline I. Pré-análise
\end{tabular}




\begin{tabular}{|c|c|c|}
\hline 1. Diagnóstico da situação & $\begin{array}{l}\mathrm{s} \\
\mathrm{s} \\
\mathrm{s}\end{array}$ & $\begin{array}{l}\text { Estabelecimento da estrutura de suporte técnico-gerencial } \\
\text { existente } \\
\text { Definição do ciclo de vida do projeto a ser desenvolvido } \\
\text { Reconhecimento do processo a ser desenvolvido } \\
\text { Levantamento das exigências regulatórias para todas as } \\
\text { instâncias do processo } \\
\text { Identificação das lacunas na disponibilidade de recursos } \\
\text { humanos } \\
\text { Identificação do staff [com conhecimento] técnico requerido } \\
\text { Reconhecimento das limitações gerenciais/operacionais, } \\
\text { considerando-se a infra-estrutura disponível, a estrutura } \\
\text { organizacional e a missão institucional (por exemplo, a } \\
\text { pertinência ou não da cultura acadêmica) }\end{array}$ \\
\hline $\begin{array}{l}\text { 2. Identificação das } \\
\text { características do processo } \\
\text { que possam gerar impacto } \\
\text { em fatores de risco, } \\
\text { custo e tempo }\end{array}$ & s & $\begin{array}{l}\text { Projetos multidisciplinares } x \text { projetos concentrados em uma área } \\
\text { específica } \\
\text { Projetos caracterizados com elevado grau de incerteza com } \\
\text { relação aos resultados esperados e elevada complexidade, em } \\
\text { função da multidisciplinaridade } \\
\text { Gestão unilateral }\end{array}$ \\
\hline
\end{tabular}

continua

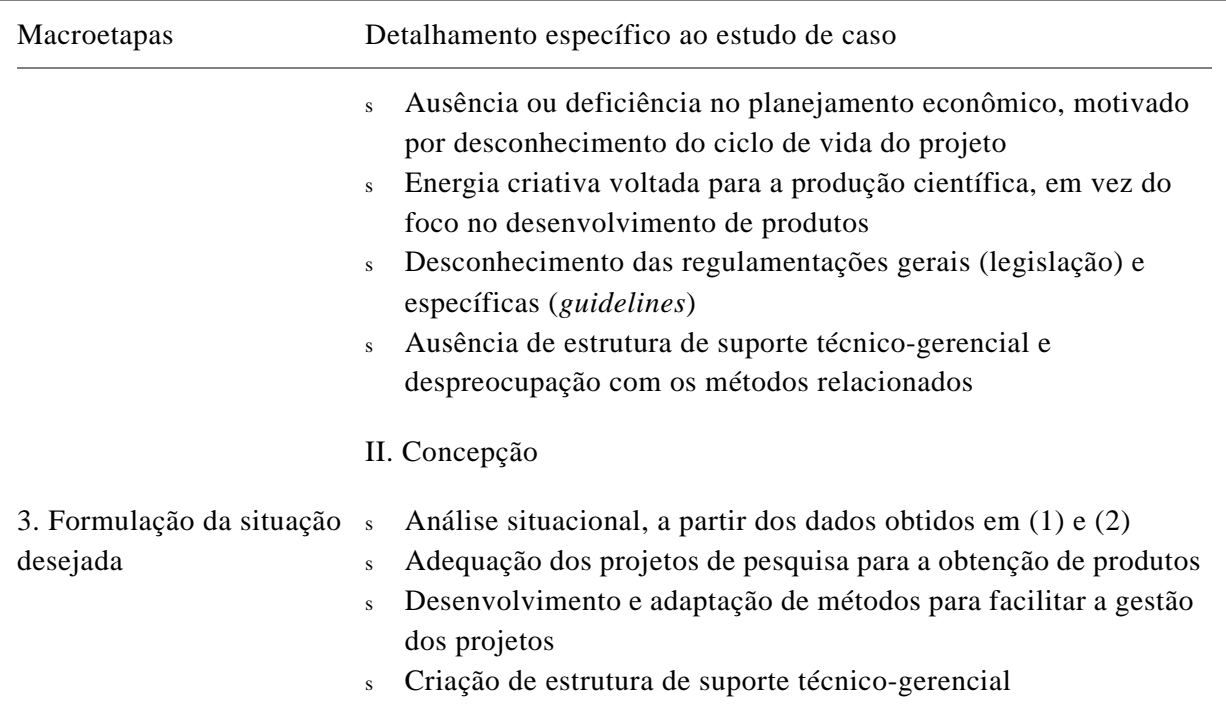


4. Objetivos

s Implantação e realização de estudos periódicos de viabilidade técnico-econômica (EVT) para os projetos, dentro de um processo gerenciado formalmente, e em conjunto com a equipe multidisciplinar

s Estabelecimento de critérios para: definições de prioridades, negociações prévias de parcerias, absorção de novos projetos e continuidade $x$ interrupção dos projetos em andamento

s Construção e estabilização das interfaces entre as fases da cadeia multidisciplinar

s Estabelecimento de critérios técnico-gerenciais e operacionais para o direcionamento dos projetos de pesquisa para a geração de produtos, dentro dos parâmetros de riscos mínimos

s Garantia de suporte técnico-gerencial aos pesquisadores

s Integração paulatina das áreas multidisciplinares no sentido de torná-las interdisciplinares

s Identificação das parcerias promissoras e necessárias

s Fortalecimento e consolidação da gestão como um todo

III. Etapa propositiva e operacional

5. Elaboração da proposta s Criação e estabelecimento de uma equipe multidisciplinar, de gestão contemplando novos cargos e funções, adequados à execução do projeto e ao gerenciamento das suas fases técnicas específicas

s Implantação de um sistema documental normativo para a agilização

e o controle institucional do processo de gestão, calcado nos conceitos do PMI

continua 


\begin{tabular}{|c|c|c|}
\hline $\begin{array}{l}\text { 6. Instrumentalização da } \\
\text { gestão para o } \\
\text { acompanhamento, } \\
\text { avaliação } \\
\text { e controle dos projetos }\end{array}$ & $\mathrm{s}$ & $\begin{array}{l}\text { Elaboração do escopo dos projetos, definindo todos os passos } \\
\text { técnicos, científicos e gerenciais desde a fase inicial da pesquisa } \\
\text { até o desenvolvimento do produto, de forma a otimizar tempo e } \\
\text { recursos, respaldados na regulamentação da área. Como } \\
\text { desdobramento gerencial, esse documento permite a } \\
\text { classificação dos projetos em níveis de acordo com o avanço } \\
\text { técnico e a cada mudança de nível a equipe multidisciplinar } \\
\text { analisa seus riscos através de um EVT } \\
\text { Elaboração de portfólio para cada projeto, contendo todas as } \\
\text { informações técnicas necessárias para subsidiar os EVTs } \\
\text { Elaboração de normas que definam os critérios a serem } \\
\text { estabelecidos no compartilhamento de dividendos com os } \\
\text { eventuais parceiros, quando da negociação sobre os direitos de } \\
\text { propriedade intelectual e industrial atinentes ao projeto } \\
\text { Utilização de ferramentas e sistemas informatizados de } \\
\text { acompanhamento de projetos }\end{array}$ \\
\hline
\end{tabular}

\section{Outras aplicações da metodologia desenvolvida}

A metodologia gerencial desenvolvida em Far-Manguinhos foi disseminada, tendo sido possível observar sua aplicação em diferentes áreas na Fiocruz que possui outras 14 unidades técnico-científicas, que exercem atividades distintas como pesquisa, ensino, extensão, serviços e produção, dentro de um modelo federativo com alto grau de autonomia gerencial.

\section{Instituto de Tecnologia em Imunobiológicos (Bio-Manguinhos)}

Em Bio-Manguinhos, unidade da Fiocruz voltada para a pesquisa, o desenvolvimento e a produção de vacinas e kits/reagentes para diagnóstico laboratorial, identificouse a necessidade da construção de um arcabouço gerencial que promovesse a interface entre as áreas de pesquisa e produção, e direcionasse os projetos de pesquisa para o desenvolvimento de produtos tecnológicos. Nessa ocasião, aproveitou-se a experiência desenvolvida em Far-Manguinhos, uma vez que a metodologia gerencial aplicada àquela unidade poderia ser adaptada aos projetos de pesquisa e desenvolvimento na área de vacinas, kits e biofármacos. Em 2002, após a criação da assessoria em gerência de projetos, Bio-Manguinhos deu início aos primeiros esforços para a adaptação e aplicação da referida metodologia.

Foram tratados dois aspectos de fundamental importância, que caminharam em paralelo, cujos objetivos são os resultados tecnológicos. O primeiro refere-se ao diagnós- 
tico da área de desenvolvimento tecnológico, apontando todos os problemas existentes e a situação desejada visando uma gestão por projetos. Nesse sentido, a estrutura organizacional foi redesenhada seguindo os moldes da estrutura matricial funcional (Maximiano, 2002), e os projetos, que antes eram vinculados às áreas físicas, foram organizados por programas tecnológicos. Surgiram novas funções, que serviram para selar a nova filosofia de trabalho, e foram definidas e estabelecidas suas responsabilidades. Como metodologia para implementação da nova filosofia de trabalho dentro da organização, foram formadas comissões compostas de representantes das áreas de interface, para que todas as áreas colaborativas dos projetos fossem envolvidas no processo. Essa reengenharia gerencial objetivou fundamentalmente promover e ampliar a difusão interativa do conhecimento organizacional, no sentido de induzir a contínua inovação (Nonaka, 1997).

Com relação aos projetos, foi elaborada uma metodologia para o acompanhamento e o controle das atividades, calcada na definição do escopo das áreas tecnológicas organizadas, semelhante ao modelo desenvolvido em Far-Manguinhos. A definição desse escopo gerou um documento, que hoje é utilizado como base metodológica pelos tecnologistas e pelos profissionais que atuam nas áreas de gestão. As técnicas de gerenciamento utilizadas foram as estabelecidas pelo PMI. Também foi elaborada uma metodologia de acompanhamento e de controle para o processo de mudança organizacional.

Os principais resultados contemplam uma maior visibilidade das etapas a serem desenvolvidas, onde se destaca o foco na obtenção de produtos, propiciando também as condições favoráveis ao processo de inovação, e promovendo uma maior integração das diferentes áreas de conhecimento técnico da unidade.

\section{Programa de Desenvolvimento Tecnológico em Insumos para a Saúde (PDTIS)}

A metodologia desenvolvida em Far-Manguinhos está sendo aplicada agora no gerenciamento de programas horizontais. Em 2002, a Fiocruz lançou o Programa de Desenvolvimento Tecnológico em Insumos para a Saúde (PDTIS) com o objetivo de estimular a pesquisa aplicada e o desenvolvimento tecnológico visando à obtenção de produtos e processos com impacto na saúde pública e no controle de doenças infectoparasitárias. Estruturado sob a forma de redes cooperativas, o programa reúne diferentes grupos de pesquisa, de várias unidades da Fiocruz e em diversas áreas científicas. Ao final de 2003, quase 40 projetos integravam as três primeiras redes formadas: Rede Cooperativa de Medicamentos, Rede de Vacinas Recombinantes e de DNA e a Rede de Proteoma e Genoma Fucional. Visando obter subsídios para o aperfeiçoamento do PDTIS, Pinheiro (2004) identificou obstáculos que poderiam comprometer o alcance dos objetivos pretendidos, como: o elevado número de pro- 
jetos de alta complexidade nas redes, a baixa interação intra e inter-redes, a cultura acadêmica vigente, a ausência de sistemas gerenciais específicos para cada rede, uma equipe gerencial insuficiente em relação à quantidade e complexidade de projetos, entre outros.

A autora observou a experiência desenvolvida em Far-Manguinhos e propôs sua adaptação e aplicação ao caso do programa, como uma alternativa viável para o gerenciamento dos diferentes projetos, nas várias redes, levando-se em consideração as especificações de cada área. Esse processo está hoje em fase de implantação em todas as redes do programa.

\section{Considerações finais}

O desenvolvimento tecnológico visando a geração de inovações ainda é um campo a ser efetivamente estimulado no país, tanto em instituições de pesquisa quanto em empresas nacionais. O gerenciamento da $\mathrm{P} \& \mathrm{D}$ em organizações de base acadêmica, entretanto, conforme indicado por Debackere (2000), requer a criação de contexto, estrutura e processos apropriados dentro das organizações.

Nesse contexto, destaca-se o importante papel das inovações organizacionais e gerenciais como suporte ao desenvolvimento de novos produtos ou processos. Novas formas de organização que estimulem a criação sinérgica do conhecimento através da promoção do intercâmbio entre diversas áreas parecem ser uma tendência.

A busca por novas formas de organização, conforme salientado por Lundvall (2001), inicia-se pela busca de maior base de conhecimento com pesquisas sobre organizações que tenham adotado diferentes modelos organizacionais e gerenciais. Assim, a metodologia de gestão de projetos de pesquisa voltados para a geração de produtos e processos apresentada neste artigo reflete tanto um esforço na busca por melhores práticas gerenciais no campo do desenvolvimento tecnológico, quanto a tentativa de disseminar a experiência observada como uma proposta de aplicação a outras instituições.

A metodologia foi desenvolvida tendo em conta especificamente o processo de P\&D como ocorre nos IPPs e por isso a imaginamos de maior utilidade para essas organizações tão carentes de ferramentas específicas.

Ainda, a metodologia desenvolvida em Far-Manguinhos vem sendo adaptada e aplicada a diversas áreas de atuação da Fiocruz, demonstrando amplo escopo potencial de utilização.

Referências bibliográficas 
ALBUQUERQUE, E.; CASSIOLATO, J. E. As especificidades do sistema de inovação do setor saúde: uma resenha da literatura como introdução a uma discussão do caso brasileiro. São Paulo: FeSBE, 2000. 151 p. (Estudos FeSBE I).

BRASIL. MINISTÉRIO DA SAÚDE. FIOCRUZ. Critérios para a normatização dos dividendos da comercialização de produtos desenvolvidos através de parcerias. Rio de Janeiro: Instituto de Tecnologia em Fármacos, s.d.

—. - Remédios para o Brasil. Rio de Janeiro: Instituto de Tecnologia em Fármacos, 2002.

CALDAS, R. A. A construção de um modelo de arcabouço legal para ciência, tecnologia e inovação. Parcerias Estratégicas, Brasília, n. 11, p. 5-27, 2001.

DEBACKERE, K. Managing academic R\&D as a business at K.U. Leuven: context, structure and process. R\&D Management, v. 30, n. 4, p. 323-328, 2000.

LUNDVALL, B. Políticas de inovação na economia do aprendizado. Parcerias Estratégicas, Brasília, n. 10, p. 200-218, 2001.

MAXIMINIANO, A. C. A. Administração de projetos. São Paulo: Atlas, 2002.

NONAKA, I. A empresa criadora de conhecimento. In: STARKEY, K. (Org.). Como as organizações aprendem. São Paulo: Futura, 1997.

PINHEIRO, A. A. Gestão de programas horizontais: o caso do Programa de Desenvolvimento Tecnológico em Insumos para a Saúde (PDTIS) da Fiocruz. 2004. Dissertação (Mestrado) — Escola Nacional de Saúde Pública Sérgio Arouca, Fundação Oswaldo Cruz, Rio de Janeiro.

PIZARRO, A. P. B. Gestão de projetos. Seminário realizado no MPGC\&TS/ENSP/Fiocruz, em 2 jun. 2003.

PMI (PROJECT MANAGEMENT INSTITUTE). Guide to the project management body of knowledge $\mathrm{PMBOK}{ }^{\circledR}, 1996$.

ROUSSEL, P. A.; SAAD, K. N.; BOHLIN, N. Pesquisa e desenvolvimento: como integrar P\&D ao plano estratégico e operacional das empresas como fator de produtividade e competitividade. São Paulo: Makron Books, 1992.

VALERIANO, D. Gerência em projetos de pesquisa, desenvolvimento e engenharia. São Paulo: Makron Books, 1998. 